\title{
De Estero en Estero': \\ Construcciones Educativas de las Comunidades Negras del Pacífico Sur Colombiano en Medio del Conflicto Armado
}

RINCÓN, Jorge Enrique García²

\section{RESUMEN}

Este artículo se ocupará de los procesos académicos, sociales, culturales y políticos que dieron origen a un movimiento intelectual y pedagógico del Pacifico Sur colombiano, con especial énfasis en los territorios afronariñenses. Vale aclarar que en materia de obras escritas se destacan los pensadores negros del departamento del Chocó quienes, incursionaron en el siglo XX en variados campos del conocimiento y desarrollaron una crítica fuerte al sistema de enseñanza nacional. En cambio, las experiencias educativas surgidas en la cotidianidad de los pueblos negros del suroccidente colombiano, se incubaron y consolidaron en los valles interandinos (norte del Cauca y sur del Valle), así como en Buenaventura y la Costa de Nariño. Estas subregiones, especialmente la costa del departamento de Nariño, asumieron la escuela como escenario para la eclosión del pensamiento ancestral afrocolombiano y las tradiciones culturales de sus pueblos en un intento por concretar en la práctica una ecuación política que involucra la Territorialidad como práctica de la educación.

Costa de Nariño. Etnoeducación. Sistema de educación propia. comunidades afronariñenses. Territorialidad. Conflicto armado.

\section{From estuary to estuary: educational constructions of the black communities of the Colombian South Pacific in the middle of the armed conflict}

\begin{abstract}
${ }^{1}$ Esteros son los senderos de navegación que se encuentran entre los manglares del Pacifico. En el caso de la Costa de Nariño el territorio está abigarrado de manglares laberinticos que solo los nativos de la región conocen. Los esteros son hábitat de variadas especies de animales de mar, así como aves, reptiles, moluscos y representan una fuente de vida para la población negra e indígena de la región. Existe en este territorio una relación simbiótica entre comunidades, esteros y manglares. Los pueblos negros del Pacifico sur son pueblos del manglar. Todos sus viajes se hacen a través de los esteros.

2 Professor Visitante na Universidad Del Cauca, Colômbia. Doutor em corrientes pedagógicas contemporáneas. Universidad de Nariño, UNARINO, Colômbia. Email: jegar2013@hotmail.com. Lattes: http://lattes.cnpq.br/7020960539849712. Orcid: https://orcid.org/0000-0003-4682-2125.
\end{abstract}

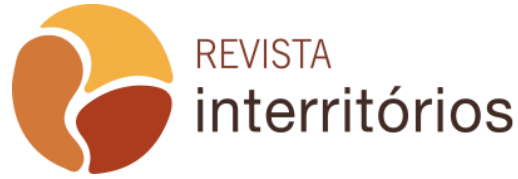

Interritórios | Revista de Educação Universidade Federal de Pernambuco, Caruaru, BRASIL | V.6 N.12 [2020] 
This article will deal with the academic, social, cultural and political processes that gave rise to an intellectual and pedagogical movement in the Colombian South Pacific, with special emphasis on the Afro-Afro territories. It is worth clarifying that in terms of written works, the black thinkers of the department of Chocó stand out, who ventured into various fields of knowledge in the 20th century and developed a strong criticism of the national education system. On the other hand, the educational experiences that emerged in the daily life of the black peoples of southwestern Colombia were incubated and consolidated in the inter-Andean valleys (north of Cauca and south of the Valley), as well as in Buenaventura and the Costa de Nariño. These subregions, especially the coast of the department of Nariño, assumed the school as the setting for the emergence of Afro-Colombian ancestral thought and the cultural traditions of their peoples in an attempt to put into practice a political equation that involves Territoriality as a practice of education.

Costa de Nariño. ethno-education. self-education system. afronariñenses communities. Territoriality. Armed conflict.

\section{De estuário a estuário: construções educacionais das comunidades negras do Pacífico Sul colombiano em meio ao conflito armado}

\section{RESUMO}

Este artigo discutirá aspectos acadêmicos, sociais, culturais e políticos que deram origem a um movimento intelectual e pedagógico no Pacífico Sul colombiano, com especial ênfase para os territórios de afronariñenses. Vale ressaltar que, em termos de obras escritas se destacam os pensadores negros do departamento de Chocó, que influenciaram no século $\mathrm{XX}$, em diferentes áreas do conhecimento e desenvolveram uma forte crítica do sistema de educação nacional. Por outro lado, as experiências educativas que surgiram da cotidianidade dos povos negros do sudoeste colombiano, incubaram e se consolidaram nos vales interandinos (norte de Cauca e sul do Valle), bem como em Buenaventura e a costa de Nariño. Estas sub-regiões, especialmente a costa do departamento de Nariño, assumiram a escola como cenário para o surgimento do pensamento ancestral afro-colombiano e das tradições culturais de seus povos na tentativa de concretizar na prática, uma educação política que envolve a Territorialidade como prática de educação.

Costa de Nariño. Etno-educação. Educação Própria. Comunidades afronarinenses. Territorialidade. Conflito armado.

\section{Dall'estuario all'estuario: costruzioni educative delle comunità nere del Pacifico meridionale colombiano nel mezzo del conflitto armato}




\section{SOMMARIO}

Questo articolo tratterà dei processi accademici, sociali, culturali e politici che hanno dato origine a un movimento intellettuale e pedagogico nel Sud Pacifico colombiano, con un'enfasi speciale sui territori afro-afro. Vale la pena chiarire che in termini di opere scritte, spiccano i pensatori neri del dipartimento di Chocó, che si sono avventurati in vari campi del sapere nel XX secolo e hanno sviluppato una forte critica al sistema educativo nazionale. D'altra parte, le esperienze educative emerse nella vita quotidiana dei popoli neri della Colombia sud-occidentale sono state incubate e consolidate nelle valli interandine (a nord di Cauca ea sud della valle), così come a Buenaventura e la Costa de Nariño. Queste sottoregioni, in particolare la costa del dipartimento di Nariño, hanno assunto la scuola come scenario per l'emergere del pensiero ancestrale afro-colombiano e delle tradizioni culturali dei loro popoli nel tentativo di mettere in pratica un'equazione politica che coinvolge la territorialità come pratica educativa.

Costa di Nariño. Etnoeducazione. Sistema educativo proprio. Comunità africane. Territorialità. Conflitto armato.

\section{INTRODUCCIÓN ${ }^{3 *}$}

Si bien en los archivos del Estado del Cauca ${ }^{4}$ aparecen registros desde 1888 que indican la prestación del servicio educativo en gran parte de las poblaciones del Pacífico (Tumaco, Barbacoas, Iscuandé, Magüí, Mosquera, Salahonda, Guapi, Buenaventura, Quibdó, etc.) y en pueblos nortecaucanos (Caloto, Puerto Tejada, Jamundí y otros), lo más probable es que esta educación se dirigía exclusivamente a las pequeñas elites blancas de esos poblados, herederos de los hacendados coloniales y renacientes de los dueños de enclaves mineros. Los negros, en su condición de libres, después de 1851, se dispersaron en muchos territorios, especialmente en el suroccidente del país, lo más alejado posible de las autoridades republicanas. Al respecto, se pueden encontrar dos episodios que no solo constatan el interés de los negros por una vida independiente, sino también la concepción misma que tenía el Estado sobre estas sociedades.

En 1853, como director de la famosa Comisión Corográfica, Agustín Codazzi recorrió el territorio del Pacífico en el intento de mapear por primera vez las culturas y los recursos naturales del país; su impresión sobre las poblaciones negras

\footnotetext{
$3^{*}$ Una parte de esta introducción está basada en apartados de una investigación amplia que he desarrollado sobre el pensamiento educativo de los intelectuales negros colombianos. La he traído a este articulo para mostrar el segregacionismo educativo contra la población negra y conectar esto con las dinámicas donde las comunidades confrontar y construyen políticas educativas.

${ }^{4}$ Archivo del Cauca. Revista de Instrucción Pública, II, (133). Popayán, 1891.

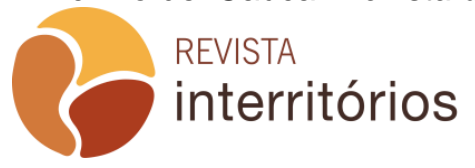

Interritórios | Revista de Educação Universidade Federal de Pernambuco, Caruaru, BRASIL | V.6 N.12 [2020]
} 
asentadas en los territorios que para aquella época correspondían a la provincia de Barbacoas fue la siguiente:

Los individuos de esta raza, antes se dedicaban a la explotación de las minas; pasan en el día, haciendo mal uso de la libertad recién adquirida, han dejado en su mayor parte este trabajo para vivir en absoluta independencia, en las orillas de los ríos, sembrando unas pocas matas de plátano, algunas de maíz y otras de caña, cuyos productos, unidos a los peces abundantes en los ríos y a los zainos y cerdos de monte, les dan un grosero pero seguro alimento. Como viven casi desnudos, con un simple guayuco los hombres, y las mujeres con una vara de bayeta sujeta a la cintura, si quieren hacerse a una muda de ropa para presentarse en el pueblo, van a las playas de los ríos a lavar arenas auríferas y en pocas horas tienen lo necesario para sus compras... Genios perversos o mal intencionados han infundido a esta gente tosca e ignorante, la idea de que no deben trabajar para los blancos y de que las tierras de estos se deben repartir entre ellos... Si Barbacoas desea progresar no debe hacerse ilusiones, esperando su porvenir de los extranjeros, ni de los vapores o de los canales... Debe buscar los medios de explotar sus minas, obligando por reglamentos severos a trabajar en ellas a la clase jornalera, so pena de considerarlos como vagos. ¿Qué sería de la República si los hombres que deben servir de peones no quisieran hacer nada, contentándose con vegetar nada más? Obligar pues a esta raza por naturaleza indolente y perezosa a trabajar para enriquecerse es hacerles un bien positivo, porque están poco más o menos como los indios semibárbaros que necesitan tutores... Si Barbacoas no toma medida semejante, se encontrará bien pronto en un estado muy triste... (CODAZZI, A. (1853) En BARONA, et al, 2002, p. 24).

Con esta percepción del Estado sobre los pueblos negros, en la segunda mitad del siglo XIX, era poco probable que la educación que se impartía para la época se dirigiera a estas comunidades. Al contrario, la visión estatal se inclinaba hacia una re-esclavización de los negros, a efectos de lograr el progreso del país. Con el informe de Codazzi, se infiere que el enfoque político colonial se mantenía vigente en la Republica, aun después de la abolición de la esclavitud, lo que equivale a decir que, en materia educativa, la población de ancestro africano no estaba en los planes del Estado.

El otro episodio que configura la imagen de la exclusión de los negros del sistema educativo en el siglo XIX se analiza en Rogerio Velásquez (2010). El autor dice que en 1894, visitó el Chocó el investigador Jorge Brisson y encontró un territorio sin institucionalidad, sin ley, sin escuelas; la gente de la región vivía en absoluta pobreza y, según su testimonio, casi salvaje. Velásquez comenta, al respecto, que: 
Con estos antecedentes, no es extraño que el negro originario del Chocó piense lo que ahora glosamos. Él no ha experimentado los beneficios de una escuela acertada, ni sentido la influencia educativa del magisterio que, en los primeros años, tuvo mucho que ver con la discriminación racial. Sin contacto con gentes capaces de elevar su nivel cultural, o en unión de seres que no ven sino su interés inmediato, el ribereño tiene que ser como es, conformista, despreocupado, individualista, hombre que ve en la lectura un lujo. Algo accesorio de lo que se puede prescindir. (p. 171).

Cuando se refiere a la discriminación racial de los primeros años, Velázquez rememora la segregación que en materia educativa vivió el Chocó en los comienzos del siglo XX (CASTILLO, 2011), asunto que Miguel A. Caicedo Mena, describirá en detalle en su libro Sólidos pilares de la educación chocoana (2011). No obstante, la mirada despectiva sobre la región y la gente negra del Pacífico que aparece en la narración de Agustín Codazzi, no se queda solo en su época; por el contrario, tendrá continuidad en obras posteriores, como la del sacerdote agustino recoleto Bernardo Merizalde (1921), donde, al referirse a la minería del oro en la parte sur de la comarca, aduce que:

Antiguamente los dueños de las minas obligaban a los esclavos a trabajar; pero en la actualidad los negros perezosos e indolentes por naturaleza se contentan con extraer al año algunas onzas de oro, lo estrictamente necesario para comprar en las fiestas anuales los menesteres indispensables para la vida. Aquellas minas están esperando que se monten maquinarias modernas dirigidas por hombres inteligentes y laboriosos para manifestar hasta donde llegan los tesoros que ocultan sus entrañas. ¿No será la minería la redención de la Costa? (p. 143).

Negros perezosos e indolentes es una frase utilizada por Codazzi, que da cuenta de la percepción de la sociedad colombiana de su tiempo sobre las poblaciones de origen africano. Estas sociedades, después de la abolición de la esclavitud, ocuparon tierras lejanas e inhóspitas como las del Pacifico para rehacer su vida social, cultural y productiva. Lo curioso es que esta frase se repite en el siglo XX, en forma exacta, en la obra del sacerdote Bernardo Merizalde, como si se tratara de una forma inmodificable de concebir al negro. Lo que Codazzi y Merizalde no son capaces de reconocer es lo que hay detrás de la manera como la gente negra del Pacífico vive su relación con la naturaleza. Su visión de mundo, su filosofía bantú, su cultura relacional, su espiritualidad, como lo han explicado algunos autores (OLIVELLA 1997, VANÍN 1993, ESCOBAR, 2003), no les permite una relación agresiva con su entorno natural. Codazzi y Merizalde leen el territorio como 
escenario de "progreso", de aprovechamiento y de poder. Por contraste con la filosofía bantú, que está basada en el respeto de la naturaleza ellos postulan las maquinarias del "progreso" y el capital como asuntos de la inteligencia humana. Esta mirada racista y colonial sobre las sociedades negras del Pacifico trascenderá en el tiempo y llegará a nuestros días bajo la representación de una cultura folklorizada y un sujeto supuestamente incapaz para comprender y convivir con el proyecto "civilizatorio"

Nos interesa aquí la investigación de Brisson en el sentido en que complementa la idea que, en el siglo XIX, la educación ofrecida por el Estado no se dirigió a las poblaciones de comunidades negras, en el entendido que, en el discurso oficial, estas gentes no calificaban como sujetos de formación. La ausencia de la escuela en los territorios negros del Pacífico se prolonga hasta bien entrado el siglo XX, como lo testimonia el mismo Bernardo Merizalde (1921):

todavía existe mucha inmoralidad en la Costa, a pesar de la transformación innegable que se ha realizado de veinte años a esta parte, merced al trabajo constante e incansable de los misioneros. La ignorancia es completa; lo que se debe a la falta de escuelas suficientes, a las grandes distancias a que viven los negros y a la incuria de los padres por el bien de sus hijos (p. 155).

Pero, la preocupación de la curia, en el puro inicio del siglo XX en el Pacífico, no es tanto la ausencia de escuelas, sino una suerte de falta de control sobre las almas de los negros que, en su vida "semisalvaje", no acatan las reglas de la Iglesia. Bernardo Merizalde percibe la llegada de los misioneros agustinos recoletos a la región como un proceso de moralización o, más concretamente, como un proyecto de conquista espiritual de la Costa (p. 170); por toda educación conciben la religiosidad católica y el acatamiento de las reglas del clero. Queda claro que la educación escolarizada en los territorios de mayoría negra en el suroccidente colombiano no estaba garantizada en las primeras décadas del siglo XX. Esta cuestión será confrontada por los intelectuales de estas comunidades especialmente en el Chocó en cuyas reclamaciones tendrán que luchar sin descanso contra los poderes de la Iglesia y las elites blancas de las regiones negras.

Como lo ha descrito Miguel A. Caicedo, después de un periodo largo de segregacionismo educativo en el Chocó, por orden oficial en 1912 se crea la primera escuela donde pueden acceder las niñas negras de Quibdó, las mismas que tendrán que esperar hasta 1934 para ingresar a la secundaria dado que la aristocracia blanca lo había impedido. Todo se había diseñado para que las negras no pasaran de la primaria y continuaran al servicio de las familias acomodadas; entre los requisitos para entrar al bachillerato estaban algunos de tipo moral, como que 
deberían ser hijas legítimas, y otros de tipo económico, donde los padres tenían que pagar, pero, en esa época, cumplir con este requisito era imposible para las familias negras. (CAICEDO, 2011, apud GARCÍA 2016, p. 98).

Cuando la educación oficial llega a los territorios de las comunidades negras del Pacifico en el siglo XX, se presenta como proyecto civilizatorio del Estado. Es decir, una educación impuesta a pueblos "ignorantes y perezosos" que necesitan de los conocimientos de la sociedad blanca para alcanzar un mínimo de moralidad, es decir humanidad. Con esta premisa instruccionista civilizatoria, el Estado inaugura la re-colonización de la gente negra por la vía de la educación. Ante este panorama, un selecto grupo de intelectuales negros del país fueron creando durante todo el siglo XX un campo epistémico educativo basado en una crítica frontal al sistema de enseñanza nacional.

En los principios de los años 90 del siglo pasado, nace el movimiento social afrocolombiano integrado por distintas organizaciones negras del país, entre ellas compañías artísticas y culturales, jóvenes, mujeres, dinámicas rurales, comunidades eclesiales de base, expresiones barriales, colectivos de maestros y capas de intelectuales, quienes siguieron la ruta trazada por los pensadores y pensadoras negras pioneros(as) de las reivindicaciones étnico-raciales en el mismo siglo. Este movimiento enfrentó los debates con la institucionalidad para encontrar un lugar como población étnica en la Constitución política de 1991. La inclusión del artículo transitorio 55 fue el gran resultado de esa gestión. Este artículo constitucional reconoce las prácticas tradicionales, productivas, espirituales y de convivencia de las comunidades negras como elemento esencial que demuestra su derecho ancestral a los territorios que ocupa. El Movimiento social generó y agenció paralelamente un movimiento pedagógico afrocolombiano que pudo visibilizar un número muy importante de experiencias educativas propias que en distintos lugares del país, desde la década de los ochenta, venían en franca oposición a las políticas públicas de educación oficiales ${ }^{5}$.

Se podría decir, sin tapujos, que las agencias del movimiento negro en los años noventa lograron algunas victorias políticas y conquistaron espacios jurídicos en materia educativa. La ley 70 de 1993 cuyo capítulo VI está dedicado a explicar la educación propia para estos pueblos. El decreto 804 de 1995, reglamentario de la ley general de Educación (ley 115 de 1994), orienta la forma como las autoridades étnicas de los territorios deben intervenir en la educación, desarrolla los principios de la etnoeducación y la administración de proyectos educativos en las comunidades. El decreto 1122 de 1998, reglamentario de la ley 70 , crea la catedra

\footnotetext{
${ }^{5}$ Ver mi libro Por fuera de la casa del amo: insumisión epistémica y pensamiento educativo afrocolombiano del siglo XX. Editorial Poemia. Cali 2019. 
de estudios afrocolombianos para ser impartida en todo el sistema público y privado de educación en el país. Infortunadamente, el pensamiento Afrocolombianos y los estudios de la Diáspora africana constituyen aun en Colombia un campo epistémico racializado. Es demasiado pobre el desarrollo de la Catedra en las universidades y en instituciones de enseñanza básica. El racismo académico sigue siendo muy fuerte en el país hasta el punto que no existe un solo programa universitario que dé cuenta de las relaciones étnico raciales. Es un tema vedado y cada vez subsumido en la perspectiva estatal de la interculturalidad que desdibuja casi por completo el proyecto histórico de auto-reconocimiento y libertad del negro en Colombia.

Ahora bien, la educación étnico-racial en perspectiva afrocolombiana, en los últimos años, está pasando de los grandes discursos basados en la ancestralidad y la defensa de los territorios a ámbitos de nuevas generaciones de juventudes universitarias que intentan seguir la huella del proceso políticos marcados por el movimiento social pero caracterizándolo desde dinámicas que privilegian enfoques e intereses más urbanos, multirraciales e interculturales, constituyendo renovados escenario para continuar la lucha. También, es muy evidente que grandes masas de población negra del Pacifico (especialmente mujeres que perdieron sus esposos en el conflicto armado) fueron obligadas a migrar forzosamente a las grandes ciudades del país, dejando atrás sus territorios en manos de los actores de la guerra. Estas poblaciones lograron niveles muy altos de organización social a través de pedagogías restitutivas que buscan la retención de discursos y practicas ancestrales, así como una gramática de la sanación y la convivencia. Estas organizaciones de mujeres (Afrodes-Las comadres y Afromupaz), sumadas a los colectivos de artistas urbanos, maestros y maestras citadinas, grupos organizados de jóvenes universitarios, así como a la creada recientemente Asociación colombiana de investigadores(as) Afros(as) ACIAFRO, están traduciendo el campo educativo propio con características territoriales muy situadas en las regiones mayoritariamente negras, a un proyecto de gestión urbana del conocimiento Afrocolombiano en dialogo con la institucionalidad.

Tal como se presenta en casi todos los países de América latina, en Colombia la tensión entre las poblaciones negras y el estado en materia de política educativa sigue siendo un espacio de grandes tensiones. Se trata de la confrontación entre el proyecto histórico, cultural y epistémico de las comunidades negras versus el recalcitrante proyecto hegemónico de las elites blancas que desarrollan todo tipo de estrategia para negar el sistema de pensamiento Afro en el currículo nacional.

En este sentido, es necesario abrir un dialogo sobre concepciones educativas, pero también sobre concepciones distintas de sociedad, epistemología, cultura y política. La construcción de proyectos educativos desde la diversidad "subalterna" en América latina implica no solamente la de-construcción de modelos 
pedagógicos impuestos, también la puesta en marcha de alternativas educativas basadas en las epistemes propias de los pueblos y en dialogo intercultural entre los mismos. La gama de posibilidades educacionales, construidas desde "la periferia" es clara muestra de la movilidad social en que se encuentran las naciones culturales latinoamericanas intentando un desajuste de las estructuras coloniales en los sistemas de enseñanza oficiales.

En ultimas, se trata de comprender la diversidad en una expresión profunda, es decir, no como formulismo de la ley sino como expresión de la complejidad en las sociedades de origen colonial y que están regidas por la democracia liberal. Comprender las identidades en los términos señalados es también de la mayor importancia en la definición de los roles sociales del individuo ya que la modernidad europea dejó instalada la falsa dicotomía Superioridad-inferioridad como patrón de convivencia, poder y división del trabajo (QUIJANO, 2000). Desmontar los mitos de la modernidad (DUSSEL, 1992) ayudaría mucho a una convivencia sana en los tiempos actuales y contribuiría a la inter-subjetividad de pueblos, etnias y culturas.

El artículo se ocupará esencialmente de la narración de los procesos educativos de las comunidades afronariñenses que condujeron a la aprobación de política pública. Las maestras y líderes de organizaciones étnico-territoriales construyeron pensamiento educativo en medio del sonido estruendoso del conflicto armado colombiano que desde finales de los noventa invadió el territorio del Pacifico sur. Este recuento urge para mantener la memoria activa, la llama ardiendo y el entusiasmo en alto. En todo caso, no es posible desconectar a un pueblo de su memoria colectiva sin producir un vacío en sus determinaciones políticas.

\section{Como inició el movimiento social y pedagógico afronariñense}

En los primeros años de la década de los noventa se da la emergencia del movimiento social afrocolombiano. La dirigencia comunitaria de la costa del departamento de Nariño no solo participó en la estructuración de este proceso organizativo, sus aportes intelectuales fueron pilares en los debates y la definición del campo epistémico que desembocará en la consolidación del discurso étnicoracial y el movimiento pedagógico afrocolombiano.

Con la inclusión del artículo transitorio 55 en la constitución política de 1991 que reconoce a los negros colombianos como comunidades étnicas, se desarrolla un proceso fuerte de construcción de nuevas concepciones educativas en el Pacifico, con mayor fuerza en el sur (Costa de Nariño). Esta región está constituida por diez municipios: Tumaco, Barbacoas, Francisco Pizarro, Maguí Payan, Roberto Payan, El Charco, Santa Barbara de Iscuandé, La Tola, Olaya Herrera y Mosquera. 
En estos procesos organizativos del sur se pueden ubicar tres escenarios donde las comunidades negras consolidan un movimiento social fuerte por los derechos colectivos. En primer lugar, el escenario post-constituyente del 1991 donde los líderes comunitarios urbanos y campesinos de los diez municipios aportan ideas clave en los debates que dieron origen a la ley 70 de 1993. En segundo lugar, como resultado de la reglamentación de la ley 70 , el proceso afronariñense incursiona en la titulación colectiva de los territorios y casi que simultáneamente inicia también la lucha por una educación que valore y respete sus prácticas ancestrales de vida. $Y$ en tercer lugar, en la dinámica organizativa del Pacifico es muy central la asociación entre educación y territorio. En gran medida en el proyecto etnoeducativo discutido con el Estado durante la década de los años noventa la educación era concebida por maestros y dirigentes comunitarios como un proceso de defensa territorial. Dicho planteamiento se puede comprender como respuesta a la lógica de la economía extractivista que domina la región desde la década de los años sesenta del siglo XX. El capital externo que entró a los territorios del sur del Pacifico colombiano con beneplácito del Estado a partir de concepciones madereras, mineras, pesqueras y enclaves económicos con las plantaciones de palma aceitera etc, fue minando las posibilidades de vida digna de los pobladores negros e indígenas en una suerte de re-esclavización y colonización permanente. Además de la destrucción de los bosques, las empresas extractivistas externas causaron gravísimos daños ambientales como la contaminación de las fuentes de agua, o el desvío del curso de los ríos para facilitar el transporte de la madera. Como se leerá más adelante, a este escenario deprimido y deshumanizado se le sumaran en los años siguientes otros problemas como el narcotráfico, las guerrillas y los grupos paramilitares configurando el territorio del Pacifico sur como el súmmum del conflicto y la guerra.

Historiar sobre los procesos que construyen alternativas educativas en la perspectiva de los pueblos negros del sur, pasa necesariamente por analizar los cuestionamientos que estas comunidades hacen frente al control de los territorios por parte de los proyectos externos llámense empresas o grupos armados en el marco del conflicto colombiano.

No obstante, para construir educación desde las iniciativas de las comunidades negras de Nariño los dirigentes han tenido que enfrentar no solamente a empresarios extractivistas y grupos armados, también a la institucionalidad educativa del departamento y del país que no dejan de imponer criterios estandarizados como mecanismo de control del discurso educativo y político de las comunidades. Mientras el discurso de la defensa de la tradición y los territorios ancestrales circula al interior de las dinámicas de reivindicación basadas en la ley 70 de 1993, el sector educativo oficial permanecía incólume en sus principios, metas 
y propósitos. Fue grande la tarea de los líderes comunitarios para mover las estructuras de la escuela oficial en el Pacifico sur. Con la transformación del movimiento social afronariñense en Palenque Regional Nariño que reunía organizaciones de los diez municipios de la costa, a la dirigencia del movimiento se suman muchos maestros de las diferentes zonas. Con esta presencia de docentes como líderes de los procesos que reclaman al estado los derechos colectivos de los pueblos negros, se podría afirmar que paulatinamente el movimiento social de comunidades negras en Nariño se va convirtiendo en un movimiento pedagógico que defiende la tierra colectiva y el proyecto de educación propia para los territorios en una suerte de gestión intelectual permanente compenetrada culturalmente y comprometida en la lucha.

En 1995, con el apoyo del Ministerio de Educación, se realizan en toda la región de la costa los primeros talleres y encuentros de maestros y líderes comunitarios en los que se socializa y se afianza el conocimiento sobre los derechos colectivos consagrados en la ley 70 . El derecho al territorio, a la identidad cultural asociada a las prácticas ancestrales productivas, espirituales y de convivencia humana van poco a poco dominando el discurso educativo que se inserta de manera fuerte en la escuela oficial. Este proceso revive y fortalece experiencias educativas que venían desde la década de los ochenta como las bandas típicas en la vereda de Robles en Tumaco que consistía en la recuperación de las tradiciones artísticas afro y su inclusión en la escuela; lo mismo ocurre con el proceso de etnoeducación en la escuela La playa municipio de Francisco Pizarro (Salahonda) cuyos maestros en un proyecto de investigación fueron tras la esencia cultural afro en un intento por transformar los poderes de la escuela oficial que ignoraba y desdeñaba los conocimientos de estos pueblos.

En 1996, la Normal superior de Barbacoas inicia su proceso de certificación como institución etnoeducativa en el marco de los debates que las comunidades negras hacen al Ministerio de educación en el sentido que las instituciones formadoras de maestros deben contemplar los saberes y practicas ancestrales de los pueblos negros dentro del conjunto de los conocimientos que estos reciben en la institución. Con esta propuesta, se buscaba garantizar que los maestros negros y no negros tuvieran el nivel de preparación suficiente para enfrentar el nuevo reto de la educación de carácter étnico-racial.

Desde 1998, por problemas internos de los líderes comunitarios que representan diferentes zonas, el Palenque Regional Nariño (máxima organización de las comunidades negras) se divide. Dicha fragmentación dio origen a tres grandes organizaciones de segundo nivel que representan igual número de subregiones de población negra en el departamento. En 2003 se crea la Red de Consejos comunitarios del Pacifico sur (Recompas) con centro poblado principal en 
Tumaco, Telembí con centro poblado principal en Barbacoas y Sanquianga con centro poblado principal en El Charco. La Costa de Nariño representa la mitad del territorio del departamento $(16.000 \mathrm{kms} 2)$ pero sus diez municipios solo alcanzan una población aproximada de 500.000 habitantes. (Gobernación de Nariño-2018).

\section{Regiones de Nariño}

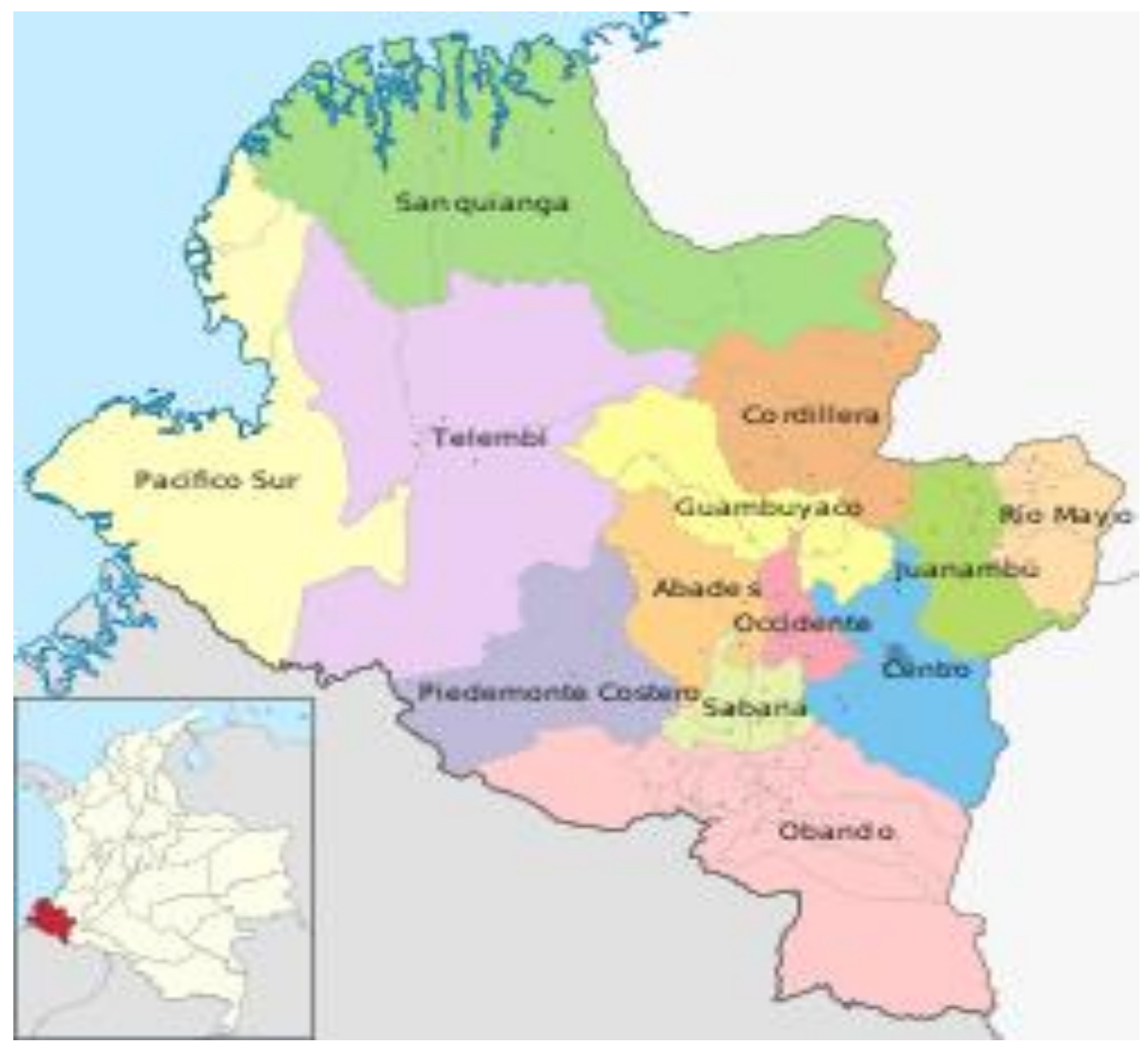

Fuente Gobernación de Nariño: regiones de Nariño.

Las grandes organizaciones negras en Nariño desde los comienzos del nuevo milenio se constituyen por separado en escenarios de negociación con el gobierno departamental y con el Estado en general. Dentro de las reivindicaciones sociales y de carácter étnico-racial, las organizaciones mencionadas tienen como uno de sus centros de gestión la educación. No obstante, no se trata de cualquier educación; en todos los eventos de concertación con las entidades oficiales los líderes de la región del Pacifico sur demandan una atención educativa diferenciada dada su condición histórica y cultural distinta pero también considerando la precariedad económica y el deterioro ambiental en sus territorios. Siguiendo los debates nacionales sobre la necesidad de una educación pertinente en territorios étnicos, las dirigencias de la costa Pacífica asumieron el concepto de etnoeducación 
para deslindar sus procesos educativos de los que impone el Estado. Al igual que en los valles interandinos, Chocó, Cauca y Valle del Cauca, los líderes y maestros dirigentes de los procesos de las comunidades negras dieron gran importancia a la etnoeducación como alternativa en la construcción de la subjetividad política de estos pueblos. La etnoeducación es concebida como un escenario de socialización de las tradiciones culturales que se estaban quedando rezagadas con el avance en la modernización de la educación en los territorios de comunidades negras. La etnoeducación también fue entendida como oportunidad para una nueva lectura de la historia, como escenario de dialogo político, el retorno del maestro líder, la eliminación de la línea divisoria entre escuela y comunidades y finalmente una apuesta por la defensa de los territorios a partir del fortalecimiento de la organización social.

Con estos elementos apropiados por la dirigencia de los procesos etnoeducativos en la Costa de Nariño, en 2004 aparece uno de los momentos más importantes de la gestión político-educativa. Con el apoyo de la WWF 6 entre marzo y julio del año mencionado se realizaron tres grandes eventos (Amarales-La Tola, Mosquera y Tumaco) El primer evento tuvo como objetivo la construcción de la ruta para concretar la realización de la Mesa Subregional de Etnoeducación. Las mesas subregionales fue una estrategia de la Comisión Pedagógica nacional de las comunidades negras (CPN) para lograr la participación de los actores comunitarios y organizaciones de la educación afrocolombiana en las regiones colombianas. En Amarales ocurre un renacimiento del proceso afro que reclama otro tipo de educación. Las reflexiones se centraron en establecer el papel de la etnoeducación en la construcción de un proyecto político para el pueblo negro. (MEMORIA AMARALES 2004, p. 11). Dicho proyecto es inviable en la estrategia estatal de estandarización, por lo tanto, la crítica de las comunidades a la política educativa oficial se hizo muy patente durante el evento. Si existe un reconocimiento de la diversidad y la política de Estado pretende que los pueblos reafirmen su identidad, se autoreconozcan y construyan proyectos de vida, ¿Cómo es posible que el mismo Estado a través del Ministerio de educación en particular promuevan una política educativa estandarizada en las tierras de las comunidades negras? Esta política niega la diversidad y la etnoeducación. Ahí está el debate (Memorias Amarales, 2004, p. 12).

El evento también se pregunta ¿Cuáles son los modelos educativos y pedagógicos que se requieren en el contexto del Pacifico teniendo en cuenta las particularidades culturales, étnicas y económicas de la región, incluyendo los problemas de violencia, el narcotráfico, el conflicto armado y la incidencia de los proyectos globales que se están desarrollando en el Pacifico? ¿En medio de esta

${ }^{6}$ Fondo Mundial para la Naturaleza. Organización ambientalista internacional. 
realidad tan compleja cómo pensamos la educación? (Memorias Amarales, p. 13). Mas la pregunta de fondo que se plantean los asistentes a Amarales es: ¿en materia educativa hacia dónde queremos ir? Y las respuestas sin titubeos de parte de los líderes comunitarios y maestros es marchar hacia la autonomía que se combina con la autoridad sobre los territorios, con la reafirmación de la identidad y la recuperación del sistema de derecho propio de las comunidades negras, pues se requiere llegar a un punto tal que podamos pensarnos como verdadera nación cultural afrocolombiana, una nación dentro de un territorio: Colombia. (Memorias Amarales, p. 14). Estas reflexiones profundamente políticas en medio del conflicto armado en la región, no dejan ser peligrosas, pero al mismo tiempo valientes.

Esa ruta de la etnoeducación como proceso de educación propia, para los asistentes, significa mirarse hacia adentro, hacer una introspección necesaria que permita encontrar la esencia humana afrocolombiana, en este caso afropacifica que ha sido negada en el sistema público de educación. La ley 70 de 1993 facilita el mirarse hacia adentro (Memorias Amarales, p. 13) y crea el escenario para construir un proyecto político y un modelo pedagógico propio a partir del cual se pueda volver a mirar hacia afuera, pero sobre la base de un afianzamiento y reafirmación de la identidad. Sin duda, los planteamientos de este primer taller de 2004 dejan una ruta de reflexiones fuertes y complejas para el taller de Mosquera. Puesta en ese nivel, la discusión político-pedagógica en el Pacifico obliga a las comunidades, líderes y maestros a organizar un evento académico de grandes dimensiones en el mes de mayo en el municipio de Mosquera.

Con los antecedentes de Amarales, el reto de los colectivos de docentes y líderes comunitarios en Mosquera era ir lo más lejos posible en el análisis teórico y conceptual de la etnoeducación en relación con la territorialidad; también precisar el papel de las dinámicas educativas como vehículo para el control de los territorios como espacios de vida. Algunos de los interrogantes que guiaron la discusión son: ¿Qué lugar tiene la escuela en el control social y la autonomía territorial? ¿qué es lo propio y qué es lo ajeno? ¿Cómo construir un proyecto etnoeducativo regional que integre todos los pueblos del Pacifico? ¿Qué actitud asumir frente a la política de estandarización? ¿Cómo la etnoeducación puede ayudar a concebir el territorio como una comarca cultural afropacifica? (Memorias, Mosquera, 2004, pp. 19-24).

Para dar respuestas a algunas de estas cuestiones, Santiago Arboleda Quiñones de la universidad del Pacifico (presente en el evento) rememora las ideas de monseñor Gerardo Valencia Cano obispo de Buenaventura hasta el año 1972 cuando muere en un trágico y sospechoso accidente. Arboleda expone que si hay una cultura y educación propia, también hay cultura y educación impuesta, la enseñanza escolar por excelencia es un ámbito de cultura impuesta. En este sentido, la visión de lo propio, de lo ajeno y de lo impuesto en el pensamiento de 
Gerardo Valencia Cano se constituye en algo muy importante. El proponía una educación para la libertad o la liberación. (Memorias Mosquera, p. 19).

Gerardo Valencia Cano estaba planteando un movimiento pedagógico regional en el menor tiempo posible y antes de que las riquezas naturales, oro, platino y bosques sean extraídos totalmente por el capital foráneo con medios violentos.

"La costa colombiana del Pacifico, arbitrariamente dividida en cuatro zonas, constituye un todo homogéneo, riquísimo en cosas y en hombres. Sin embargo, injustamente se ha hecho creer que la cultura de sus gentes no las capacita para explotar debidamente sus riquezas... ¿Qué es educar sino descubrir al hombre en sus relaciones con el ambiente para explotarlo en beneficio propio y en el de la comunidad?, "pero cuando al hombre se le oculta lo propio para enseñarle lo ajeno, ¿Qué otra cosa se hace sino convertirlo en esclavo o ladrón? La educación para la costa del Pacifico en todos los niveles sin exceptuar Buenaventura, ni Tumaco, ni Quibdó debe ser replanteada regionalmente". (VALENCIA CANO apud ARBOLEDA, MEMORIAS MOSQUERA, 2004, p. 20).

Un asunto muy importante en estas reflexiones es la discusión sobre el papel de la etnoeducación, en términos de educación propia, en la conducción de la sociedad del Pacifico que aspira lograr la autoridad sobre los territorios. Pese a que la región del Pacifico está penetrada por muchos discursos, siguen siendo los símbolos de la identidad negra, sus prácticas, su cultura ancestral lo que se percibe por fuera de la región como elementos de integridad y de intimidad social, cultural y política. Es decir, cuando se representa al Pacifico por fuera, aflora la espiritualidad, la religiosidad, la expresión corporal y toda la sabiduría de la medicina tradicional afrocolombiana. Igualmente, simbólicamente la cultura negra representa con mayor fuerza los actores y discursos del Pacifico. Por lo tanto, en los procesos educativos se debe tomar una decisión acerca del tema de la interculturalidad y diversidad cultural ya que como discurso global-occidental requiere ser re-pensado de acuerdo con el proyecto de región. (MEMORIAS MOSQUERA, p. 21).

En el decir de los asistentes al evento, la educación debe servir para lograr el control territorial en todos los sentidos, debe conducir hacia la apropiación del territorio como espacio geográfico (la tierra), pero también hacia la reafirmación étnica (la identidad), hacia la autonomía, la autoridad y la organización comunitaria como ejes de la visión política. Si la orientación pedagógica apunta hacia estos pilares, se puede lograr la gobernabilidad y la gobernanza en los territorios ya que estos temas se han identificado como débiles y como la gran problemática. Si se logra avanzar y afianzar en los pilares propuestos, el recorrido final del proceso 
pedagógico tendría que llevar a la región hacia la nación cultural afropacifica. (MEMORIAS MOSQUERA, idem).

En el municipio de Mosquera también se retomó el debate sobre la estandarización de la educación como política oficial nefasta para los intereses de los habitantes del Pacifico. La contrapuesta de las comunidades se mueve en el interés de construir el movimiento pedagógico etnoeducativo en la subregión del Pacifico nariñense y después extender el movimiento a nivel de todo el litoral, integrando subregiones e incluyendo la participación de los hermanos de Ecuador. Por eso, la pregunta ¿cómo la etnoeducación puede ayudar a concebir el territorio como comarca cultural afropacifica? Se hace en el contexto del debate sobre la estandarización propuesta por el Estado. (MEMORIAS MOSQUERA, p. 24).

El evento en Mosquera superó las expectativas de preparación de la Mesa subregional de etnoeducación. Además de definir los participantes, agenda, temáticas y logística para la próxima jornada a realizarse en Tumaco, se avanzó hacia un punto alto en las concepciones de educación en la perspectiva afrocolombiana y en la identificación de la estructura organizacional del movimiento pedagógico del Pacifico.

\section{Hacia un sistema de educación propia afrocolombiana para la costa de Nariño}

Después de los eventos preparatorios de Amarales y Mosquera, en julio 22 de 2004 se instala en Tumaco la Mesa subregional de Etnoeducación. Espacio donde confluyeron delegados del Ministerio de educación, secretaría de educación departamental, alcaldes de la costa o sus delegados, miembros de los colectivos de maestros, organizaciones étnico-territoriales (Recompas-Asocoetnar, Chonapi), líderes sociales del Pacifico, académicos, ONG's nacionales y la cooperación internacional representada en la WWF (patrocinador).

La organización del evento fue asignada a Recompas y Asocoetnar, organizaciones de segundo nivel que agrupan los consejos comunitarios de Nariño. En función de asesoría a los organizadores, también estuvo el delegado por Nariño a la Comisión Pedagógica Nacional (quien escribe). Esta jornada de trabajo se planteó varios propósitos. Concretar el proyecto de educación propia en los territorios afro de la costa de Nariño. Presentar el marco jurídico (ley 70 de 1993 y reglamentarios) que favorece la construcción de educación propia en las comunidades negras colombianas; igualmente, la presencia de los alcaldes de la región y las organizaciones étnicas de segundo nivel constituyen un respaldo 
político regional; pero además, el evento estuvo matizado por un respaldo académico dada la presencia de varias universidades.

Tal como lo visualizan los asistentes al evento de Tumaco, el proyecto de educación propia parte de la identificación de la problemática territorial de la costa nariñense que amenaza la supervivencia del pueblo afrocolombiano. El proyecto se sustenta entonces en diagnosticar lo que se entiende como territorio y territorialidad y en el papel que juega la etnoeducación en la solución de las problemáticas fundamentales en la región. De ahí que una de las preguntas que generó debate fue ¿Qué es el territorio para las comunidades negras del Pacifico? El territorio es entendido como el espacio geográfico donde la comunidad vive su cotidianidad, su esperanza, su anhelo, su resistencia, donde evidencia sus valores ancestrales y donde expresa su sabiduría con más espontaneidad. Es el escenario de vida en su función espacial y temporal. La territorialidad en cambio es entendida como la dinámica de los procesos de vida, determinada por la cultura, la historia, la naturaleza y la sociedad misma. Es el espacio simbólico donde se desarrolla y se recrea la vida de las comunidades. Es lo que permite la identidad como ser y reafirma la identidad como pueblo negro. (MEMORIAS, TUMACO, 2004, p. 34).

Para Reinelda Perlaza (maestra y dirigente comunitaria del municipio del Charco)

uno de los elementos problemáticos en la región del Pacifico sur es la falta de alternativas productivas y soberanía alimentaria, el pueblo negro vivía de la agricultura, "para nosotros lo químico no existía, teníamos un suelo fértil [...] pero los cultivos de los foráneos han causado perdida de nuestros recursos naturales nativos, de nuestros productos tradicionales y desde allí la perdida de nuestra identidad y la falta de conciencia y articulación para la dinámica escolar". También plantea esta dirigente del proceso educativo afronariñense que la educación ha sido el principal escenario donde se ha llevado al pueblo negro a la perdida de los valores, para dividir la familia como célula principal de nuestras comunidades, para llevarnos a la pérdida de identidad y para que cada día nos sintamos siendo el esclavo africano que vino a hacer reverencia a los" amos" (MEMORIAS TUMACO, p. 31).

En efecto, en la trayectoria política de América latina y del Caribe desde el periodo colonialista hasta nuestros días, educar significó colonizar y conformar un campo simbólico e ideológico de dominación a partir de lo educativo y lo pedagógico (PINHEIRO, 2015, p. 329).

Para enfrentar toda la problemática descrita, pareciera ser que las comunidades de la costa de Nariño ubican como solución única el desarrollo de un sistema de educación propia. Es una educación concebida y construida "desde 
adentro" que pretende devolver a las comunidades por los senderos de la solidaridad y la cohesión social no solamente como adarga para repeler los embates de las lógicas socio-económicas externas, sino también para re-constituirse como pueblos espiritual y culturalmente.

En el acta de acuerdos con el gobierno, firmada en Tumaco, la aspiración comunitaria a un sistema educativo propio se centró en el siguiente punto:

Diseño y establecimiento de un Plan quinquenal de etnoeducación para la costa Pacífica de Nariño, que fortalezca la identidad étnico-cultural y la gobernabilidad en los territorios afrocolombianos, el cual está comprendido en el proyecto: "Hacia un sistema de educación propia afrocolombiana para la Costa Pacífica de Nariño", cuyo objetivo general es el de fortalecer las condiciones sociales e institucionales para el establecimiento de la educación propia desde las comunidades afronariñenses. (MEMORIAS, TUMACO, p. 41).

Siendo el principal acuerdo logrado, este proyecto se desglosa en varios componentes de tipo pedagógico-curricular, educación comunitaria y para adultos, la educación superior, la investigación, la infraestructura y los aspectos organizacionales. A cada componente se le asignó responsabilidades institucionales y comunitarias.

En suma, dos grandes elementos comprenden los espacios de debate abiertos por la WWF. En primer lugar, la importancia de la etnoeducación en su papel de control y apropiación política sobre el territorio afropacifico y en segundo lugar la urgencia de un sistema educativo propio para la subregión de la costa nariñense. Sin embargo, como lo veremos más adelante, al Ministerio de Educación este tema no le interesará sino hasta los años 2009 y 2010 cuando deciden apoyar los procesos educativos afronariñenses por razones que debo explicar enseguida.

En octubre 6 de 2004, el Ministerio de educación expide el decreto 3238 con el cual reglamenta los concursos de mérito para ingresar a la carrera docente en Colombia. Este hecho marca el inicio de un proceso de debate fuerte entre los delegados de las comunidades negras a la Comisión Pedagógica Nacional ${ }^{7}$ y el gobierno. La CPN no acepta que el decreto en mención se aplique en los territorios de las comunidades negras. Los debates suscitados a partir de esta contradicción van perfilando un escenario de reconstrucción política del movimiento social afrocolombiano que había iniciado con grandes augurios en la década de los noventa ${ }^{8}$.

\footnotetext{
${ }^{7}$ La Comisión Pedagógica Nacional de comunidades negras (CPN) es la instancia de concertación entre el Estado y el movimiento social afrocolombiano en asuntos de política educativa, creada en el decreto 2249 de 1996 como reglamentación del artículo 42 de la ley 70 de 1993.

${ }^{8}$ Ver mi libro "Sube la Marea", Pasto. Edinar. 2009. (Capitulo 9). 
Ante las contradicciones con la CPN, el Ministerio de educación decide concertar con esta instancia un concurso especial para la selección de maestros afrocolombianos. Las jornadas de negociación se prolongaron a lo largo de un año y no fue posible un acuerdo entre las partes. Los delegados de las comunidades exponían los inconvenientes del concurso en tanto que no estaba basado en la legislación Afro y el MEN insistía en asegurar que la CPN aprobara el concurso que tenía el rotulo de especial pero en realidad diseñado con la misma estructura de los concursos nacionales abiertos.

Por considerar agotada la discusión con la CPN, el MEN expide el 21 de septiembre de 2005 el decreto 3323 mediante el cual convoca a concurso "especial" a los maestros afrocolombianos en todo el país. Con esta imposición del Ministerio, un grupo de la CPN, (incluido quien escribe), propone la desobediencia civil al decreto ministerial. El liderazgo de los maestros afronariñenses fue vital para consolidar el movimiento pedagógico afrocolombiano que se tomó en dos ocasiones la iglesia de San Francisco en el centro histórico de Bogotá en protesta por el desconocimiento por parte del MEN de los derechos educativos de las comunidades negras. La primera toma se hizo en noviembre de 2005 y sirvió de escenario para una negociación más amplia con el Estado que incluía, además de los problemas derivados del concurso docente, otros temas de crucial importancia para la población afrocolombiana.

A partir de la toma de la iglesia, vinieron varios actos de desobediencia civil al concurso de maestros afro, especialmente en el Pacifico sur con gran protagonismo de los colectivos docentes de Tumaco y la costa de Nariño. Para asegurar un dialogo por canales legales entre las comunidades afronariñenses y la autoridad educativa departamental, en 2006, mediante decreto 1690 se crea la Mesa Departamental de educación de las comunidades negras de Nariño. Este espacio de concertación da continuidad a la Mesa subregional que inició en 2004 y proponía la creación de un sistema de educación propia afronariñense.

Concentrados en la desobediencia civil al concurso de maestros afro, esta Mesa discute periódicamente con las autoridades departamentales y propone un concurso ajustado a la legislación étnica afrocolombiana en donde la selección del maestro no la hace el Estado sino las comunidades entre miembros preferiblemente de sus propios territorios. Los líderes docentes del proceso afronariñense alegaron de todas las formas que un eventual concurso abierto no solo no tenía piso legal, sino que constituía un atentado contra la estabilidad laboral de los maestros negros del Pacifico, pero fundamentalmente una agresión cultural sin precedentes. No hay que olvidar que la lucha afropacifica en contra del concurso docente está centrada en las diferencias de esta región con otras regiones afro del país. En concreto, el MEN decide someter a concurso un promedio de ocho mil plazas docentes de toda 
la región del litoral desde el Chocó hasta Tumaco ocupadas por maestros de los territorios en provisionalidad con 10, 15 y hasta 20 años de servicio. Para el resto del país afro, el gobierno asigna unas pocas plazas nuevas por departamento y eso generó la división entre los miembros de la CPN.

Pasando por encima de la legislación especial y sin asignar ninguna plaza docente nueva para el Pacifico, el gobierno pretendía poner los puestos de trabajo de los maestros negros en la lógica de un concurso abierto nacional con las implicancias de tipo cultural, social y político que representa una acción de este calibre para las poblaciones negras. Es claro que las reclamaciones de los dirigentes afronariñenses estaban enmarcadas en el derecho étnico pero también en el conocimiento del racismo estructural característico del Estado colombiano.

Después de la desobediencia civil al concurso, en varias ocasiones las organizaciones de comunidades negras de Nariño recibieron la visita del Ministerio de educación en 2009. Curiosamente, el MEN ofreció apoyo financiero para la construcción del Proyecto Etnoeducativo Afronariñense. (PRETAN). Cuatro organizaciones de segundo nivel asumieron el reto de trabajar con sus comunidades en más de noventa eventos comunitarios para formular el proyecto etnoeducativo que se constituye en una guía conceptual, pedagógica y operativa para viabilizar los procesos de transformación de la educación en las comunidades afronariñenses. EI PRETAN contiene cinco grandes aspectos así: a) Un aspecto Conceptual, que define Pensamiento propio afronariñense, educación propia, etnoeducación, currículo propio entre otros aspectos, b) un componente pedagógico que establece como modelo el "Aprendizaje colectivo", define unos fundamentos y ejes de aprendizaje, escenarios de aprendizaje comunitarios, la importancia de la investigación, la evaluación participativa así como las funciones de la etnoeducación y el perfil de los docentes. c) Un componente administrativo que re-distribuye las responsabilidades de la administración educativa asignando un rol a las autoridades étnicas y a las comunidades de base (padres de familia, líderes y organizaciones y consejos comunitarios), d) Un componente prospectivo que define los proyectos que se requieren en materia pedagógica y administrativa para la puesta en marcha del sistema educativo propio. La educación propia es concebida en el documento PRETAN asi:

En el marco del pensamiento propio se encuentra inscrita la educación propia que es entendida aquí como "la que se imparte desde la identidad cultural afronariñense y se define como un proceso político, social, económico, ambiental, espiritual y cultural de construcción participativa y colectiva, desde el territorio, que se sustenta en la legitimación de las raíces ancestrales de la comunidad, en sus propias construcciones de significado, historia, 
idiosincrasia y experiencia; potenciando las capacidades que han construido los pueblos a través de los tiempos, articulándose a los avances en el conocimiento, cultura, ciencia y tecnología, estableciendo un diálogo de saberes, de respeto y valoración mutua". (Documento PRETAN, 2012, p. 15).

Después de un largo periodo de validación con las comunidades e instituciones, el PRETAN es declarado Política Publica departamental de educación para las comunidades negras de Nariño mediante ordenanza 037 de noviembre de 2013. Esta política hace posible, en teoría, el anhelo de las comunidades de contar con sistema de educación propia afronariñense, basado en la promoción de la cultura negra o Afro. No se trata de la inclusión folclorizada de la cultura negra en la estructura del proyecto oficial de educación (CÓRDOBA, 1980), sino de una concepción política resultante de una perspectiva distinta de la cultura. Para mi tengo, que la cultura tiene que ver fundamentalmente con la realización, acumulación y transformación de las construcciones epistémicas de un pueblo, nación o sociedad. La transformación puede estar asociada a procesos históricos de intercambio espontaneo con otras sociedades o puede ser que un pueblo 0 comunidad sea afectada por la imposición cultural.

\section{Pensar la educación en medio del fuego de los fusiles}

Durante 20 años el discurso educativo de los pueblos negros del pacifico sur en Colombia hubo que construirlo en medio de la guerra. En primera instancia, las tomas guerrilleras de los municipios dejaron desolación, muerte y terror. Los diez municipios de la costa pacífica nariñense sufrieron las invasiones guerrilleras y las incursiones paramilitares. El conflicto armado que vive Colombia penetró hasta el último rincón de la geografía racializada del Pacifico. Las guerrillas de izquierda (FARC y ELN) avanzaron en el territorio desde mediados de la década de los 90, imponiendo autoridad y desplazando comunidades. A partir de la década del 2000 los paramilitares (Brazo armado irregular a favor del estado) imponen la necropolitica (Mbembe) no para enfrentar las guerrillas sino para ejercer poder sobre la población. Los crímenes de los paramilitares resultaron más crueles que los de las guerrillas y la región se ahoga en la sangre y la barbarie.

Las hipótesis que se utilizan con más frecuencia atribuyen las causas de la violencia armada en la región a cinco aspectos generales: el olvido histórico al que ha sido sometida esta zona del país y el abandono institucional del Estado, la precariedad del desarrollo económico a causa de prácticas extractivistas desde el tiempo de la Colonia, la distribución y los problemas de propiedad de tierras, la corrupción de la clase política local y la entrada del narcotráfico. (RODRIGUEZ, 
2015). Mas impactante todavía, confirmar que en la medida que ese proceso expansivo de la guerra coincide con territorios étnicos específicos, sean estos indígenas o negros, se profundizan y exacerban hasta extremos inimaginables en todos los sentidos y dispositivos del racismo, el etnocidio y el terror que, al parecer siempre han estado ahí, dormitando en lo mas profundo de la conciencia colectiva de los colombianos. (ALMARIO, 2004, p. 79).

En efecto, la llegada del conflicto armado a la región del Pacifico sur colombiano coincide con los procesos de defensa de los territorios ancestrales que las comunidades negras inician a partir de la expedición de la ley 70 de 1993. Hay aquí una suerte de consigna inconfesada: se les entrega la tierra, pero se les vuelve a quitar violentamente. La llegada del paramilitarismo muy al final de la década de los 90 confirma también que el control de estos grupos sobre los territorios, no solo buscaba enfrentar a las guerrillas, es ante todo un obstáculo político-militar con el que se pretende desactivar el movimiento social afrocolombiano aun en embrión. El paramilitarismo se hizo aún más peligroso cuando se dedicaron al negocio del narcotráfico (RODRIGUEZ, p. 52) reconfirmando la región como escenario de guerra e imponiendo nuevo orden social.

Entre tanto, los maestros, en medio de los fusiles, insisten en el debate pedagógico-cultural que defiende las tradiciones afropacificas como elementos esenciales del currículo. Es muy claro que el magisterio de esta región quería mostrar la necesidad de las prácticas culturales y espirituales como sistema de sanación, resiliencia y resistencia creativa frente al conflicto armado.

No obstante, es evidente que las tradiciones y prácticas de vida en general de las comunidades negras de Nariño están siendo reemplazadas por dinámicas asociadas a formas de ser de otros contextos del país que se mueven en la lógica de la violencia como patrón de convivencia. Los paramilitares, las guerrillas, los narcotraficantes y todo tipo de bandas delincuenciales han impuesto en esta región nuevos códigos de comportamiento y nuevas formas de ser y percibir lo social, lo cultural y lo político en una suerte de estrategias de control del pensamiento en estos pueblos. De ahí los asesinatos sistemáticos de los dirigentes comunitarios que desarrollan gestión intelectual en la defensa de sus territorios. El caso de concreto de la muerte de Genaro Garcia, quien, en defensa de la cultura y el territorio, acompañó las jornadas de desobediencia de los maestros, es un caso explicativo del control del discurso político étnico-racial. El Pacifico sur, en el decir de la Corte Constitucional es una región que se desenvuelve en un escenario de drama humanitario. La corte expidió los autos 005 de 2009, 073 de 2014 y el auto 620 de 2017 para ordenar al gobierno una serie de medidas en favor de las comunidades afectadas, desplazadas y confinadas. De acuerdo con la Corte, los autos están amparados en el reconocimiento de las comunidades negras de Nariño 
como sujetos de especial protección constitucional ${ }^{9}$. No obstante, el presidencialismo colombiano desconoce el ordenamiento jurídico del país y desdeña la jurisprudencia de las Cortes siempre que tales sentencias favorezcan a las minorías políticas de la piel más oscura. Uno de los aspectos que la Corte menciona es la educación. En el Auto 005 de 2009 incluye el concepto de Enfoque Diferencial para referirse a la atención que los gobiernos deben prestar para resolver las problemáticas sentidas de las comunidades afrocolombianas. Con relación a la educación en los territorios de las comunidades negras el auto es explícito en establecer que "un enfoque diferencial a favor de la población afrocolombiana en materia de educación exige no solo facilidades y oportunidades para el acceso a la educación sino también una educación adecuada a sus condiciones étnicas y culturales". Este concepto de la Corte no es asumido por el Ministerio de educación en la medida en que el mismo representa una trasgresión del currículo nacional que ha sido diseñado como proyecto civilizador y como currículo colonizado (SILVA, 1997, p. 73).

La política pública de educación afronariñense es un logro de la dirigencia y la intelectualidad negra del departamento de Nariño y la primera en establecerse en el país como desarrollo de la legislación étnica afrocolombiana. El objeto de la política pública es reconocer a las comunidades negras del departamento de Nariño el derecho a una educación que valore, respete y desarrolle su identidad cultural en los niveles de educación inicial, básica, media y superior de acuerdo con los intereses sociales, culturales y políticos de estas poblaciones. (ORDENANZA 037 de 2013, p. 15).

Sin embargo, todo el esfuerzo realizado y los debates sostenidos con el departamento y el Estado en general, los dirigentes de los procesos etnoeducativos en los territorios afronariñenses observan con escepticismo las posibilidades de aplicación de la política pública toda vez que varios años después de su aprobación no se identifica ninguna estrategia para su promoción. Salvo el intento de la cooperación internacional (Save the Children y Consejo Noruego para refugiados) por hacerla conocer, no existe una dinámica institucional ni comunitaria para que dicha política pueda ser una realidad en las escuelas.

A pesar de que la política pública en una de sus estrategias plantea: "vincular a los educadores que laboran en los territorios afronariñenses a través de un proceso de selección especial, con enfoque diferencial y con la participación de los consejos comunitarios como autoridades educativas competentes" (art. $10 \mathrm{de}$. 804/95) (ORDENANZA 037 de 2013, p. 20), el gobierno y la CNSC $^{10}$ siguieron

\footnotetext{
${ }^{9}$ Auto 005 de 2009.

10 7. Comisión Nacional del Servicio Civil. Es la entidad que organiza los concursos de mérito para acceder a cargos públicos en Colombia. 
adelante con los procedimientos del concurso que las comunidades habían rechazado 10 años atrás. Esto obliga a los maestros y líderes sociales de la Costa de Nariño a una nueva toma de la iglesia de San Francisco en Bogotá en julio de 2015.

Convencidos de la ilegalidad del concurso de maestros afrocolombianos, los dirigentes Afronariñenses continuaron sus batallas jurídicas contra el Estado. Apegados a la legislación educativa especial, interponen muchas demandas, tutelas y acciones populares desde el 2008. Solo hasta el 2016, la Corte constitucional acepta una tutela y la falla en favor de las comunidades. Toda la lucha de más de 12 años en que el movimiento social afronariñense confrontó con el gobierno se vio recompensada con la sentencia C-666 de 2016 en la que la Corte expone dos elementos fundamentales que le otorgan la razón al proceso de desobediencia civil en Nariño: el primer aspecto es reconocer que el decreto 1278, mediante el cual se ordenan los concursos de méritos en educación no aplica para los territorios de las comunidades negras; y en segundo lugar, la Corte ordena al gobierno la expedición de un estatuto especial que regule la carrera docente en contextos territoriales de población Afro.

Los triunfos de nivel jurídico que han obtenido las comunidades afronariñenses, sin embargo, no parecen resolver el problema del todo. Pese a las grandes movilizaciones, el concurso fue impuesto por el MEN y la CNSC ${ }^{11}$ en 2013. Lo que indica que los más de 500 maestros de la Costa de Nariño que perdieron sus cargos tendrán que iniciar nuevas batallas jurídicas para la restitución de sus derechos. Si bien el panorama de la violencia que asesina líderes sociales en la Costa de Nariño se recrudece con mucha frecuencia, esa estrategia de control del pensamiento no ha limitado del todo la manifestación de los maestros que están siempre dispuestos a iniciar una nueva movilización.

\section{CONCLUSIONES}

Las comunidades negras del Pacifico colombiano, especialmente las poblaciones de la costa del departamento de Nariño, desde la década de los años ochenta del siglo XX construyen un ideario político-educativo a contrapelo de la política oficial de educación. Es más, para toda iniciativa de educación propia, estos pueblos tuvieron que enfrentar al Estado para lo cual desarrollaron un variado conjunto de estrategias: debates con las autoridades educativas oficiales, foros académicos, movilizaciones, acción jurídica, etc. 
Si la intención del MEN al apoyar procesos organizativos de Nariño que construyen educación propia, era desmovilizar estos pueblos institucionalizando su discurso político-pedagógico, se podría decir con franqueza que hemos sido testigos del fracaso del Estado. En efecto, la primera desobediencia al concurso se hizo en 2006 y como la percepción de la institucionalidad no cambiara, se hizo necesario nuevos procesos de desobediencia. No fueron en vano los noventa encuentros comunitarios en donde se construyó el PRETAN Proyecto etnoeducativo afronariñense, la movilidad de los maestros, la presencia de los mayores, los aportes de los dirigentes, las voces de los estudiantes todo ello atravesado por la narrativa oral del Pacifico no solamente consolidó el proyecto educativo, también aseguró la resistencia de las comunidades ante la imposición institucional. Esto explica la segunda toma de la iglesia de San Francisco en Bogotá en 2015.

En el suroccidente colombiano, es el Pacifico sur, tierra marcada históricamente por la esclavización de africanos desde el siglo XVII en los enclaves mineros de Santa Bárbara de Iscuandé y Barbacoas (ALMARIO Y CASTILLO, 1996), donde mayores avances se evidencian en la construcción educativa de iniciativa social y comunitaria. Las poblaciones negras del Pacifico han confrontado al Estado desde las primeras décadas del siglo XX, inicialmente desde las voces de sus intelectuales más consagrados que han cuestionado descarnadamente el sistema público de educación y después al final del siglo por el movimiento social afrocolombiano en su conjunto, defendiendo las concepciones educativas propias a partir de la realización de experiencias pedagógicas críticas en distintos lugares del Pacifico (BUENAVENTURA, TUMACO, FRANCISCO PIZARRO, QUIBDÓ, entre otras).

Desde el Pacifico sur, las comunidades negras han interpelado la educación estandarizada al tiempo que proponen, basados en la legislación étnica afrocolombiana, la autonomía en el manejo de la educación. En este camino que ha intentado romper los rígidos esquemas oficiales, estos pueblos lograron triunfos jurídicos. Sin embargo, el multiculturalismo de la democracia liberal colombiana sostiene aun el doble juego de inclusión-negación en donde los pueblos que tienen derechos colectivos son asumidos en la normatividad pero burlados en la práctica. En gran medida el racismo estatal-colonial se sigue imponiendo sobre los pueblos e impidiendo el desarrollo de la subjetividad colectiva en perspectiva étnico-racial. No hay duda que detrás de las leyes aprobadas en favor de las comunidades negras se esconde una visión racista del Estado colombiano que he llamado en otro lugar Racismo multicultural (GARCÍA, 2018)

Todos los logros de las comunidades negras de Nariño en materia organizacional, la desobediencia civil al concurso de docentes, la defensa del territorio y los avances de tipo jurídico mediante los cuales se aprobó la política 
pública de educación en esta región, solo fueron posibles a partir de un proceso en el que los intelectuales dirigentes (en su gran mayoría maestros) fueron zumbando de estero en estero por los pueblos negros del manglar para reconectar las comunidades en torno a un proyecto de autonomía educativa que no solo pretende descolonizar la educación, sino también descolonizar el pensamiento comunitario.

Los recuentos de los procesos que construyeron educación en perspectiva de las comunidades negras de Nariño dejan claro que el reconocimiento de la diversidad no desactiva la primacía del racismo en las sociedades modernas; y por esa razón, la convivencia entre el modelo de homogenización cultural y el proyecto de diversidad étnico-racial es posible en la medida en que se trata de la coexistencia de dos discursos institucionalizados que no se interpelan en sentido práctico. Otra cosa es cuando el discurso político-educativo de las comunidades negras se construye por fuera de la institucionalidad y en franca contradicción con la misma. Este proceso autonómico de educación, del que hablan los pueblos negros del Pacifico colombiano, responde a la crítica y cuestionamiento del modelo de enseñanza oficial que desconoce todos los sistemas de pensamiento del país para centrar la educación en la matriz eurocéntrica del conocimiento. Eso es lo que se conoce en Colombia como la educación estandarizada. Es decir, aquella que sigue los lineamientos de la economía mundo y reduce las cuestiones más esenciales de los pueblos étnico-raciales a asuntos del mercado.

Las construcciones educativas de las comunidades negras en el Pacifico sur colombiano, en la actualidad, se siguen desarrollando en medio de la guerra. El acuerdo de paz entre las Farc y el gobierno no ha representado cambio alguno en la dinámica del conflicto en estos territorios. Al contrario, cada vez es más dramático el escenario en donde se mueven las comunidades, rodeadas de un indeterminado número de grupos armados que coparon los territorios dejados por las FARC-EP y que ahora siembran el terror en los territorios, asesinan y desplazan poblaciones en forma sistemática. Estos grupos armados, por fuera de toda ideología política, están dedicados exclusivamente al narcotráfico. Por lo tanto, la movilidad del pensamiento político-educativo de las comunidades negras en el Pacifico sur sigue enfrentando al Estado y a su guerra.

\section{REFERENCIAS BIBLIOGRÁFICAS}

ALMARIO Y CASTILLO, (1996). Territorio, poblamiento y sociedades negras en el Pacifico sur colombiano. En: Renacientes del Guandal: "grupos negros" de los ríos Satinga y Sanquianga. Bogotá. Proyecto Biopacifico, Ministerio del Medio Ambiente. 
ALMARIO, Oscar. (2004) Dinámicas y consecuencias del conflicto armado en el Pacifico colombiano. Limpieza étnica, desterritorialización de afrocolombianos e indígenas y "multiculturalismo de estado e indolencia nacional. En: Conflicto e invisibilidad, retos en los estudios de la gente negra en Colombia. Popayán. Universidad del Cauca. Pp. 73.120.

ASAMBLEA DEPARTAMENTAL de Nariño, (2013) ordenanza 037: Política publica de educación para las comunidades negras de Nariño. Pasto.

ASOCOETNAR et al., (2011). Proyecto etnoeducativo afronariñense PRETAN. Tumaco: Ministerio de Educación.

BARONA, G. et al. (2002). Obras Completas de la Comisión Corográfica: geografía física y política de la confederación granadina. Cali: Feriva.

CAICEDO Mena, M. A. (2011). Sólidos pilares de la educación chocoana. Quibdó: Ed. "Hebron".

CASTILLO. E. (2011). "La letra con raza, entra". Racismo, textos escolares y escritura pedagógica afrocolombiana. En: Pedagogía y Saberes (34, 61-73).

CÓRDOBA, A. S. (1980). Cultura negra y avasallamiento cultural. Bogotá: MAP publicaciones.

DA SILVA, T. (1997). Descolonizar el currículo: estrategias para una pedagogía crítica. (Dos o tres comentarios sobre el texto de Michael Apple). En: Cultura, política y currículo: ensayo sobre la crisis de la escuela pública. Pablo Gentile (Comp.) Buenos Aires. Editorial Lozada S.A.

DUSSEL, E. (1994). El encubrimiento del otro. Hacia el origen del mito de la modernidad. Quito: Ed. Abya-Yala.

ESCOBAR, A. (2003). "Mundos y conocimientos de otro modo”. El programa de investigación de modernidad/colonialidad latinoamericano. Tabula Rasa, (1), 51-86.

GARCIA, J. (2009). Sube la marea: educación propia y autonomía en los territorios negros del Pacífico. Pasto: Edinar.

GARCIA, J. (2016). Por fuera de la casa del amo: insumisión epistémica o cimarronismo intelectual en el pensamiento educativo afrocolombiano siglo XX. Pasto. Universidad de Nariño.

GARCIA, J. (2018). Interculturalidad y racismo en el circuito centro periferia: Contribución critica en la perspectiva de las negritudes. Revista ABPN (Asociación brasilera de pesquisidores negros). pp. 27-56.

MEMORIA-TALLER. Avances y acuerdos en la planificación del proceso de etnoeducación o educación propia en territorios del área de manglar del departamento de Nariño. Amarales- La Tola-Nariño, marzo 17 y 18 de 2004. WWF. 
MEMORIA-TALLER. Territorio y Etnoeducación: preparatorio de la Mesa Subregional de Etnoeducación para la Costa Nariñense. Mosquera-Nariño. Mayo 13 y 14 de 2004. WWF.

MEMORIA-TALLER. Mesa Subregional de Etnoeducación: Hacia un sistema de educación propia afrocolombiana para la Costa de Nariño. Tumaco-Nariño. Julio 22 de 2004. WWF.

MERIZALDE del Carmen, Padre B. (1921). Estudio de la Costa colombiana del Pacífico. Bogotá: Imprenta del Estado mayor general.

PINHEIRO, Lia. (2015) Resistencia histórica y memorias colectivas en América Latina: construyendo pedagogías insumisas, insumiéndose desde otras educaciones. En:

Pedagogías insumisas. Patricia Medina Melgarejo compiladora. Universidad de artes y ciencias de Chapas-Mexico.

QUIJANO, A. (2000). Colonialidad del poder, eurocentrismo y América latina. En: E. Lander (comp.). La colonialidad del saber: eurocentrismo y ciencias sociales.

Perspectivas Latinoamericanas. Buenos Aires: Clacso.

RODRÍGUEZ, José Darío, (2015) Genesis, actores y dinámicas de la violencia política en el Pacifico nariñense. Bogotá. Pontificia Universidad javeriana.

VANIN, A. (1993). Cultura del Litoral Pacífico. En: P. Leyva (ed.). Colombia Pacífico. Tomo II. Bogotá: Pablo Leyva Ed.

VELÁSQUEZ, R. (2010). Apuntes socioeconómicos del Atrato medio. En: Ensayos Escogidos. Bogotá: Ministerio de Cultura.

ZAPATA OLIVELLA, M. (1997). La rebelión de los genes. Bogotá: Ediciones Altamir. 